\title{
Academic and Personal-Social Adjustment Challenges of University of Cape Coast Freshmen
}

\author{
Sylvester Tenkorang ${ }^{1} \quad$ Linda Dzama Forde ${ }^{1 *} \quad$ Eric Nyarko-Sampson ${ }^{2}$ \\ 1.Counselling Centre, University of Cape Coast, Cape Coast, Ghana \\ 2.Department of Guidance and Counselling, University of Cape Coast, Cape Coast, Ghana
}

This research was self-funded by the researchers

\section{Abstract}

This study was carried out to investigate the common adjustment challenges freshmen in the University of Cape Coast experience during their first year in school, and the coping strategies they used in response to the adjustment challenges. A mixed model research design was used in carrying out the study. A sample of 355 students made up of 235 males and 120 females was selected through purposive and proportional stratified random sampling techniques. Adapted forms of the Student Adaptation to College Questionnaire (SACQ) developed by Baker and Siryk (1999) and the Ways of Coping Questionnaire (WCQ) developed by Folkman and Lazarus (1988) were used along with a semi-structured interview. Quantitative data was analysed descriptively while qualitative data was analysed thematically. The study found that freshmen in the University of Cape Coast encountered adjustment challenges such as difficulty handling the academic pressure and lack of involvement in social activities. In terms of coping, most respondents adopted Planful Problem Solving strategies which involved planning, concentrating and taking action to resolve issues. It was recommended that university authorities make the timetable of freshmen more flexible to enable them cope with the academic pressure.

Keywords: Adjustment, Challenges, Coping, Strategies

DOI: $10.7176 / \mathrm{JEP} / 11-18-07$

Publication date:June 30th 2020

\section{Introduction}

There is increased pressure ons every young person to pursue higher learning. In Ghana, institutions of higher learning include universities or colleges, nursing training colleges, colleges of education and polytechnics. However, university education in Ghana is seen as a critical must have for young people because university is perceived as not only the best time of life but also a stepping stone for better careers (Madilo, 2009). Freshmen in universities usually have expectations about university life long before actually leaving home (Al-Qaisy, 2010). Some students look forward to university education and are eager to experience more freedom and adventure while others may be enthusiastic initially, but then discover that the actual experience falls short of their expectations. However, these exciting years of adjustment can be undermined by several challenging situations and experiences (Dyson \& Renk, 2006).

Life in university could trigger different reactions among freshmen (Habibah, Noordin \& Mahyuddin, 2010). The increased personal freedom of being in the university can feel wonderful presenting the opportunity to become more individualistic because parental control ceases in the university and students are confronted with the new found freedom (O'Neill cited in Mudhovozi, 2012). Some of the students may not feel happy, comfortable, or secure in their new environment. Freshmen in the university therefore have to reconstruct their personal relations in the new environment and this often causes mental and physical distress (Tao, Dong, Pratt, Hunsberger, \& Pancer, 2000). In the University of Cape Coast, freshmen are admitted every academic year and take usually a period of two weeks before serious academic work starts. The first few weeks of these freshmen in the university can thus be challenging.

\section{Problem Statement}

According to Rausch and Hamilton (2006), the majority of students who drop out of university do so in the first year. The university environment is different from other school environments. Transition of students from high school and colleges to university could cause a psychological, academic and social shock to students because the university educational system has huge differences when compared with the high school environment (Thawabieh \& Qaisy, 2012). These differences include new methods of teaching, new academic requirements, new type of relations between students and faculties and even new relations among students themselves.

In Ghana, some studies such as those by Forde and Brenya (2012), Akwensivie, Ntiamoah and Obro-Adibo (2013) and Ackah and Kuranchie (2015) have been conducted about students' adjustment in Universities. However all these studies focused only on foreign students' adjustment experience in Ghanaian tertiary institutions. By paying attention to local students, this current study would cover what had been left by most of the studies done in Ghanaian universities on students' adjustment. The current study on the academic and personal-social adjustment challenges of local university students in Ghana was therefore considered urgent. 
In the University of Cape Coast, freshmen are likely to be faced with the same challenges that freshmen in other schools in other parts of the world face. Per the observation of the researcher in the University of Cape Coast, when freshmen enter the university, most of them have difficulty meeting the demands and pressures of academic work such as waking up early for lectures and quizzes. Again, some of the students appear to be alienated in their social lives since the university environment is new to them and associating with all the new peers and colleagues seem difficult to them. Investigating into academic and personal-social adjustment challenges of University of Cape Coast freshmen is therefore necessary.

\section{Purpose of Study}

The purpose of this study was to identify the common academic and personal-social adjustment challenges freshmen in the University of Cape Coast experience during their first year in school and the coping strategies they adopt to cope with these adjustment challenges. Specifically, the study was aimed at finding out the following:

1. the common academic adjustment challenges of freshmen of the University of Cape Coast,

2. the common personal-social adjustment challenges of freshmen of the University of Cape Coast,

3. the coping strategies that freshmen adopt to navigate their way through these challenges.

\section{Research Questions}

The following research questions guided the current study:

1. What are the common academic adjustment challenges experienced by freshmen of the University of Cape Coast?

2. What are the common personal-social adjustment challenges experienced by freshmen of the University of Cape Coast?

3. What coping strategies do freshmen of the University of Cape Coast adopt to navigate their way through these challenges?

\section{Literature Review}

\subsection{Theoretical Review}

Theories that were reviewed in relation to the study in this chapter included the Transactional Theory of Stress and Coping (TTSC), Coping-based Models of Adaptive Functioning, General Needs Satisfaction Theory, Social Identity Theory, Social and Behavioural Adaptation Model, Transition Theory and the Gullahorn and Gullahorn (1963) W-curve Model of Adjustment. These theories were all related to the problem under study since they all dealt with how freshmen adjust to the challenges they encounter in the university.

The Transactional Theory of Stress and Coping (TTSC) was reviewed because it was concerned mainly with how an individual perceives a situation and how that perception influences how the individual adjusts to the situation. Thus, it was suitable for the study because how a freshman perceives his/her new environment can influence his/her ability to adjust to the new environment. The Coping-based Models of Adaptive Functioning views an individual's ability to adapt to an environment as dependent on the resources at the individual's disposal. The theory was thus reviewed because it would highlight the resources that freshmen need to be able to successfully adjust to the university environment.

Furthermore, the General Needs Satisfaction Theory was reviewed in the study because it is assumed in the theory that freshmen would adjust better in their new environment when their needs are satisfied. The Social Identity Theory was of relevance in the study because the theory assumes that how freshmen are received in the new school environment influences their identities. This in turn influences their adjustment in the new environment. The interactions that freshmen have when they enter the new environment are considered to have an influence on their general level of adjustment. This is the focus of the Social and Behavioural Adaptation Model, making it a model of relevance to the study.

The Transition theory which views adjustment as a function of the situational factors, self-factors, supports and strategies also have relevance to the current study. This is because the adjustment of freshmen is assumed to be influenced by all the factors considered by the Transition theory. Finally, the W-curve model of Gullahorn and Gullahorn (1963) gave a presentation of the life stages of freshmen. This made it a model relevant to the study.

\subsection{Conceptual Framework}

The conceptual framework on which the study was based was an adapted model of the Baker and Siryk's (1989) Student Adaptation to College Model. The model had four different sections. This included the academic adjustment, personal-social adjustment, emotional adjustment and the coping strategies used in mitigating the adjustment challenges. In adapting the model of Baker and Siryk to this study, only three of the forms of adjustment were considered. Institutional attachment was however not added to the framework because it had to 
do more with whether students remained in school. In addition to those forms, an additional factor, coping strategies was added. Coping strategies was added to show how students adjusted to the adjustment challenges they experienced in the various areas of adjustment.

\subsection{Academic adjustment problems experienced by freshmen}

University is a place of academic work and as such students are likely to encounter several academic adjustment problems in their freshmen year in the university. A study by Cooke, Beewick, Barkham, Bradley, and Audin (2006) in the United Kingdom, identified several factors that cause a lot of problems for freshmen with academic pressure being a major basis for increased levels of anxiety in freshmen. The participants in the study of Cooke and his colleagues rated far worse than the general population in measures of psychological well-being, attributing this to the increased academic pressure.

In Malaysia, Ahmad, Fauziah, Azemi, Shaari and Zailani (2002) carried out a study and found that the adjustment problems faced by freshmen included difficulties in academic work such as course registration, understanding textbooks, and early morning lecture. In a similar light, Ngwenya (2004) found that freshmen had difficulty adjusting to the different styles of teaching compared to the high school. Quite predictably on the basis of the above studies, Wong, Cheung, Chan, Ma, and Tang (2006) suggested that many students in Hong Kong are folding under the academic pressure and expectations. They further indicated that students were identified as particularly vulnerable to mental health issues, with rates of depression measured at $20.9 \%(n=1657)$ and anxiety at $41.2 \%(n=3262)$. They concluded that the impact of such findings is expected to be seen in poorer academic attainment and quality of life. Burgess, Crocombe, Kelly and Seet (2009) reported that failure to meet the wider challenges faced by students during the transition from secondary to tertiary education impacts on learning outcomes. This was so because the pressure of the academic work in the university is different from that of the senior high school. The studies reviewed imply that students have a great burden of adjusting to the academic pressure of the university because of the transition process from senior high school to university.

\subsection{Personal-Social Adjustment Problems Experienced by Freshmen}

In an environment such as the university it can understandably be a place for several personal and social relations, as such as there can be adjustment issues. In the study of Ahmad et al. (2002) in Malaysia, apart from academic difficulties, participants were also found experiencing several health and financial problems. The health problems were attributed to feeling tired very often. The financial difficulties were however attributed to inability of students in receiving funds. Some of the financial problems reported by the participants were traced to lateness in receiving funds from guardians and sponsors, however, in some cases the funds received were insufficient to cater for the expenses incurred during the course of their studies.

The study of Mutambara and Bhebe (2012) in Zimbabwe showed that more than half of the respondents of 115 indicated that it had not been easy being on their own for the first time and having to take responsibility for their actions. However, a greater percentage of students in the study of Mutambara and Bhebe did not have any problems with coping with stress at campus. Parker, Summerfeldt, Hogan and Hogan (2004) indicated that upon entry into a university, first year students are confronted with new personal and interpersonal challenges that include the need to establish new relationships and modify existing relationships with parents and their families. This was in confirmation to what had been indicated earlier by Tinto (1996). These studies confirm the presence of personal-social adjustment difficulties of first year students. This has created interest in studying the personalsocial adjustment problems of freshmen in the University of Cape coast.

\subsection{Coping Strategies of Freshmen to Adjustment Problems}

Coping can be defined as cognitive and behavioural attempts or effort used to alter events or circumstances that are threatening (Dressler, as cited in Smith \& Renk, 2007). Dressler suggested that the adaptive ability of new undergraduates depends a lot on their coping effort as well as the coping strategies used to deal with the challenges and demands faced on campus. Brissette, Scheier, and Carver (2002) carried out a study for 89 first year college students. They found a significant relationship between 'active coping' $(r=-0.34, p<0.01)$ and 'positive reinterpretation and growth/PRG' $(\mathrm{r}=-0.38, \mathrm{p}<0.001)$ thereby affecting academic work positively. Several studies have also supported this view that adjustment and coping among first year undergraduates have a strong impact on their academic achievement in the universities in which the students are enrolled in (Sennett, Finchilescu, Gibson, \& Strauss, 2003).

In terms of specific coping strategies, Park and Adler (2003) investigated the effects of coping styles on 139 university incoming medical students from the University of California. Their findings pointed to the claim that coping affects academic work. Their study reported that students' coping styles was related to students' psychological well-being. Escape-avoidance coping was related to lower levels of psychological well-being, while both 'positive reappraisal' and 'planful problem solving' were marginally related to higher levels of psychological well-being. It was reported that these two coping strategies predict lesser deterioration in physical 
health.

\section{Sample}

A sample of 355 freshmen in UCC was selected via purposive and stratified random sampling techniques for this study. The sample was made up of 235 males and 120 females. The sample was drawn from four out of the five colleges in the University of Cape Coast. These were the College of Agriculture and Natural Sciences, College of Education Studies, College of Humanities and Legal Studies and the College of Health \& Allied Sciences. The College of Distance Education was not included in the study because the students in the college do not reside on the University campus.

Purposive sampling was used in choosing freshmen as the target group for the study and also in getting the eight participants for the interview data. The eight respondents selected equally on the basis of gender. Thus it was made up of four males and four females. Proportional Stratified random sampling was used to put the sample into strata of gender (male and female) and the four colleges. The sample size of each stratum was obtained by calculating on the basis of the population of the stratum within the main population. The actual respondents were then sampled randomly.

\section{Methods and Materials}

The study adopted the concurrent triangulation mixed methods. In this approach the researcher collects both quantitative and qualitative data concurrently and then compares the two data to determine if there is convergence, differences, or some combination Thus, both quantitative and qualitative approaches were used. The Student Adaptation to College Questionnaire (SACQ) developed by Baker and Siryk (1999) and the Ways of Coping Questionnaire (WCQ) developed by Folkman and Lazarus (1988) were adapted in collecting the quantitative data while a researcher-designed interview guide was used in collecting the qualitative data.

The SACQ consists of 67 self-rating statements and made up of four sub-scales, Academic, Social, Personal-Emotional and Institutional attachment that measure four types of university adjustment dimensions (Baker \& Siryk, 1999). The adapted version for the current study had 16 items made up of two sub scales (Academic and Personal-Social). This adaptation was done to cover the main variables for the study. The SACQ was on a scale of 1 for 'Yes', 2 for 'No', and 3 'Not Sure' for positive items. The reverse was used for the negative items.

The WCQ comprised of 50 items and was used to assess respondents' efforts in coping with adjustment challenges encountered in the university. This was adapted to comprise 15 items that covered the three typical ways of coping. These were Seeking Social Support (SSS), Escape-Avoidance (EA), and Planful Problem Solving (PPS) categories. The WCQ was on a scale of 0 for 'Not used', 1 for 'Used Somewhat', 2 for 'Used quite a bit', and 3 for 'Used a great deal'.

The interview guide was designed by the researcher and was semi-structured. Thus, even though it had three major questions concerning the academic challenges, personal-social challenges and coping strategies of the freshmen, other questions were asked depending on the responses given by the participants.

Validity of the questionnaire and interview guide was established by experts in counselling and students' adjustment challenges. The Cronbach-alpha co-efficient used in estimating the internal consistency provided an $\mathrm{r}$ value of 0.7 for the SACQ was and 0.7 for the WCQ. The reliability of the interview guide was however determined by inter rater reliability. Inter-rater reliability refers to the consistency or degree of agreement between two or more scorers, judges, or raters. Thus, in the case of an interview, two raters should make similar assessments of the content of the interview (Gibson, 2014). Two different raters assessed the contents of the interview and the percentage of agreement between the two raters was $90 \%$.

Ethical issues considered in the study were informed consent, autonomy, anonymity and confidentiality. Consent was sought from respondents before the study is carried out. The respondents were informed about the study so that they knew exactly what they were being asked to do, and the risks involved. This was be done by providing the consent information on the first page of the questionnaire. Participant autonomy was ensured in the sense that the participants were not forced to answer the questionnaire in a way desired by the researcher.

With anonymity, the questionnaire did not require the names of participants and their exact ages. Dummy names were also used to describe the respondents in the interview data. In the case of confidentiality, the privacy of the data collected was ensured. The participants were ensured of confidentiality by indicating it on the first page of the questionnaire and also before the interview started. The transcripts of the interview data were kept personally in secret so that no individual could have access to them.

Data collected was analyzed using the Statistical Product and Services Solution (SPSS) version 21 software. Descriptive statistics was used for the analysis of the research questions. Specifically, research question one which sought to find the common academic adjustment problems of freshmen in the University of Cape Coast was analysed using frequencies and percentages. Again, research question which dealt with the personal-social adjustment problems of freshmen in the University of Cape Coast was analysed using frequencies and 
percentages. The research question three which dealt with the coping strategies to the adjustment problems of freshmen in the University of Cape Coast was analysed using means and standard deviations. The interview data was analysed using thematic analysis and the results used in supporting the results from the quantitative data.

\section{Results}

Research Question 1: What are the common academic adjustment challenges experienced by freshmen of the University of Cape Coast?

In answering this question, respondents were provided with statements to which they had to indicate 'Yes', 'No' or 'Not Sure'. The data on this research question was analysed using frequency counts and percentages. The results are presented in Table 1. Also direct quotations of respondents are used as a form of analysis to support or triangulate the quantitative results.

Table 1: Common Academic Adjustment Challenges of UCC Freshmen

\begin{tabular}{|c|c|c|c|c|c|c|}
\hline \multirow[t]{2}{*}{ Statement } & \multicolumn{2}{|c|}{ Yes } & \multicolumn{2}{|c|}{ No } & \multicolumn{2}{|c|}{ Not Sure } \\
\hline & f & $\%$ & $\mathbf{f}$ & $\%$ & $\mathbf{f}$ & $\%$ \\
\hline Had clear academic goals & 263 & 74.7 & 51 & 14.5 & 38 & 10.8 \\
\hline Had no motivation to study & 76 & 21.7 & 243 & 69.2 & 32 & 9.1 \\
\hline Found academic work very difficult & 185 & 52.7 & 122 & 34.8 & 44 & 12.5 \\
\hline Had no focus on academic work & 47 & 13.5 & 272 & 77.9 & 30 & 8.6 \\
\hline Had serious challenges concentrating & 134 & 38.1 & 170 & 48.3 & 48 & 13.6 \\
\hline Could not attend lectures regularly & 49 & 13.9 & 295 & 83.8 & 8 & 2.3 \\
\hline Understood what was taught at lectures & 184 & 52.3 & 74 & 21.0 & 94 & 26.7 \\
\hline $\begin{array}{l}\text { Was comfortable with the academic pressure (lectures, quizzes and } \\
\text { assignments) }\end{array}$ & 85 & 24.0 & 225 & 63.6 & 44 & 12.4 \\
\hline
\end{tabular}

\section{Source: Field Survey}

Table 1 reveals that $74.7 \%$ of the respondents indicated 'Yes' to having clear academic goals in their first few weeks in the university while $14.5 \%$ of the respondents indicated 'No' to the same statement. Majority of the respondents $(69.2 \%)$ indicated 'No' to having no motivation to study in their first few weeks in the university. Thirty two $(9.1 \%)$ of the respondents indicated that they were not sure. More than half of the respondents $(52.7 \%)$ also indicated that they found academic work very difficult in the first few weeks in the university.

Table 1 shows again that majority of the respondents $(83.8 \%$ ) had been able to attend lectures regularly in the first few weeks of the semester. However, $64 \%$ of the respondents indicated that they were not comfortable with the academic pressure (lectures, quizzes and assignments) in the first few weeks of the semester.

The findings were supported by the responses gathered from the interview data. When the participants were asked to indicate the common academic adjustment challenges they had faced since they came to school, the views of the participants were not too varied. Almost all the eight respondents (7) interviewed indicated that they had challenges with the academic pressure in the university. Half (4) of the respondents interviewed also indicated that they found academic work very difficult. These views were supportive the findings in the quantitative data since the quantitative data showed that $63.6 \%$ of the respondents were not comfortable with the academic pressure in terms of lectures, quizzes and assignments while $52.7 \%$ of the respondents indicated that they had difficulty with academic work.

Some of the critical statements of the respondents are captured below:

"I had a challenge with the academic pressure... all the moving here to there was difficult", Pearl.

"... the academic pressure...there was too much on the time table, for Lab Tech, 19 credit hours, and with the practicals and the other stuff, it was tiring", Ben.

"Dealing with the unannounced quizzes was a challenge, because even if you learn you don't do well. Imagine what would happen if you don't learn", Sandra.

Research Question 2: What are the common personal-social adjustment challenges experienced by freshmen of the University of Cape Coast?

In answering this question, respondents were provided with statements to which they had to indicate 'Yes', 'No' or 'Not Sure'. The data on this research question was analysed using frequency counts and percentages. The results are presented in Table 2. Critical statements from the interviewed respondents are used in supporting the findings of the quantitative data. 
Table 2: Common Personal-Social Adjustment Challenges of UCC Freshmen

\begin{tabular}{lrrrrrr} 
& \multicolumn{1}{c}{ Statement } & Yes & & No & \multicolumn{2}{c}{$\begin{array}{c}\text { Not Sure } \\
\text { f }\end{array}$} \\
& f & \% & f & \% & f \\
\hline Fitted in well & 142 & 40.1 & 168 & 47.5 & 44 & 12.4 \\
Was involved in social activities & 123 & 34.7 & 218 & 61.4 & 14 & 3.9 \\
Got along very well with roommates & 267 & 75.2 & 66 & 18.6 & 22 & 6.2 \\
Able to socialise well with opposite sex & 180 & 50.7 & 125 & 35.2 & 50 & 14.1 \\
Really enjoyed life & 111 & 31.3 & 152 & 42.8 & 92 & 25.9 \\
Felt quite lonely & 147 & 41.6 & 159 & 45.0 & 47 & 13.3 \\
Wished I was at home rather than school & 102 & 28.8 & 215 & 60.7 & 37 & 10.5 \\
Felt comfortable with religious activities & 272 & 77.1 & 47 & 13.3 & 34 & 9.6 \\
\hline
\end{tabular}

Source: Field Survey

Table 2 shows that $75 \%$ of the respondents got along very well with their roommates in the first few weeks in the university. Similarly, $77 \%$ of the respondents indicated that they felt comfortable with religious activities in their first few weeks in the university. However, $61 \%$ of the respondents indicated that they had difficulty getting involved in social activities in the first few weeks in the university. Table 3 also shows that significant proportion of the respondents did not fit in well in the University $(47.5 \%)$ and therefore felt quite lonely $(41.6 \%)$. Regardless, the respondents did not wish they were at home instead of at school $(60.7 \%)$.

The findings were supported by the responses gathered from the interview data. All the eight respondents interviewed indicated that they had challenges with interacting with all the new people they came to meet in school while almost all the respondents (7) indicated that they had issues fitting in and enjoying the university life. These views corroborated the findings from the quantitative data.

Specifically, some of the statements of the respondents are quoted. They include:

"I had a difficulty interacting with people because of the different backgrounds", Abena.

"...It was not easy for me because I was the only one from my senior high school; I had no friends around so it was difficult for me socially", Pearl.

"Meeting all the different people from different places made it difficult for me to fit in and enjoy life", Robert.

Research Question 3: What coping strategies do freshmen of the University of Cape Coast adopt for/to mitigate the adjustment challenges they experience?

In answering this question, respondents were provided with statements which reflected different coping strategies they used to navigate adjustment challenges. The categories of coping strategies are Escape Avoidance, Planful Problem Solving and Seeking Social Support. Each category consisted of five specific coping strategies. The data under this research question were analysed descriptively using means and standard deviations. The responses under each category of coping strategy were put together and their means and standard deviations computed. The results are presented in Table 3.

Table 3: Coping Strategies of UCC Freshmen

\begin{tabular}{lll}
\hline Item & Mean & Standard Deviation \\
\hline Escape Avoidance & 4.79 & 3.11 \\
Planful Problem Solving & 9.99 & 3.96 \\
Seeking Social Support & 6.99 & 4.15 \\
\hline
\end{tabular}

Source: Field Survey (2016)

Table 3 shows that Escape Avoidance coping strategies had a mean of 4.79 and a standard deviation of 3.11 . Responses of 'Planful Problem Solving' had a mean of 9.99 and a standard deviation of 3.96 and responses of 'Seeking Social Support' had a mean of 6.99 and a standard deviation of 4.15. This implies that the most used coping strategy was planful problem solving.

The findings were supported by the findings from the interview data which made known that most of the respondents interviewed indicated that they usually planned and took action to cope with adjustment challenges. Some of the critical statements of the interviewed respondents are captured below:

"I handled most of the things I encountered on my own, I apportioned my time well", Ben.

"In terms of my academics I learnt more and I learnt before the lecturer came to teach", Pearl.

"I allocated time for myself to be able to handle the academic pressure and the stress in the university", Kofi.

\section{Discussion}

The study showed that the common academic adjustment challenges as indicated by the respondents included discomfort with academic pressure (lectures, quizzes and assignments) and difficulty with academic work. These findings are in line with the findings of Wong et al. (2006) who suggested that many students in tertiary institutions in Hong Kong are folding under the academic pressure and expectations. In a similar vein, the findings of the current study give support to the findings of Cooke et al. (2006) in the United Kingdom also found that academic pressure coupled with difficulty in academic work increased the levels of anxiety in 
freshmen. The findings were also not different from those obtained by Ahmad et al. (2002) in Malaysia on the adjustment challenges faced by freshmen undergraduates. The challenges included difficulties in academic work such as course registration, understanding textbooks, and early morning lectures.

The similarity between the findings of the current study and the other findings (Wong et al., 2006; Cooke et al., 2006 \& Ahmad et al., 2002) could be attributed to the course content at tertiary level is much more loaded than the secondary level across the world. In the University of Cape Coast, students start lectures at 6:30am and end at 9:30pm. This time schedule could be problematic for freshmen who are coming from educational backgrounds where school typically started at 7:00am and ended by 4:00pm. In this sense, respondents discomfort with the academic pressure is understandable. It needs to be stressed however lectures do not span the entire duration. There are intermittent breaks. Again, some quizzes written in the University of Cape Coast come off at dawn from 4:00am while some other quizzes were written unannounced at lecture hours. Waking up at 4:00am write a quiz could be burdensome for any freshman. In terms of the writing of unannounced quizzes, the nature of academic life in the University of Cape Coast makes writing a quiz you did not have time prepare for a very tough one to handle for most students.

The study also revealed that the common personal-social adjustment challenges of respondents in the first few weeks in the university included: not getting involved in social activities, not fitting well in the university environment and not really enjoying life. However, getting along with roommates, socialising with the opposite sex, feeling quite lonely, wishing to be at home rather than school and feeling comfortable with religious activities were not indicated by majority of the respondents as common personal-social adjustment challenges. These findings support the findings of Parker et al. (2004) who also found that upon entry into a university, first year students are confronted with new personal and interpersonal challenges that include the need to establish new relationships and modify existing relationships with parents and their families. The findings again supported that of Dyson and Renk (2006) who found that social adjustment is seen in the difficulty students have in their immediate environment, participating in social activities and their satisfaction with various social aspects of the university experience. The similarity between the findings of the current study and that of Parker et al. (2004) and Dyson and Renk (2006) suggest that freshmen students everywhere experience social adjustment challenges in their first few weeks in the university.

With regard to how freshmen mitigated adjustment challenges, the study revealed that freshmen mostly adopted planful problem solving strategies. This finding implies that the most used category of coping strategies was Planful Problem Solving with a mean of 9.99 and a standard deviation of 3.96. Next to Planful Problem Solving was Seeking Social Support while Escape Avoidance was the least used category of coping strategies. This means that most of the respondents in the current study used strategies such as simply concentrating on what I had to next, making a plan of action and following it and changing something so things would turn out all right. Other strategies within Planful Challenges Solving category included drawing on strategies/lessons learnt in earlier times and coming up with different solutions to challenges faced. These findings are in line with the findings of Seyedfatemi et al. (2007) that the coping strategies that respondents adopted were active challenges solving strategies. Similarly, the findings of the current study give support to the findings of Sreeramareddy et al. (2007) in Nepal that the most used coping strategies among respondents were active coping strategies such as planning rather than avoidant strategies. In further confirmation, the findings of the current study are in consonance with the findings of Al-Dubai et al. (2011) that the students used active coping strategies such as planning more than avoidant strategies. This implies that most students in any location usually adopt positive, planning and active coping strategies. In the University of Cape Coast, the orientation services provided for freshmen where they are taught several life management practices such as how to manage their time could be responsible for they adopting planful problem solving strategies. They face the adjustment challenges positively.

\section{Conclusions}

The common academic adjustment problems of UCC freshmen in their first few weeks in the university include: not being comfortable with the academic pressure (attending lectures, quizzes and assignments) and finding academic work very difficult. From this, it can be concluded that freshmen in the University of Cape Coast have problems with the academic pressure and academic work in their first few weeks in the university.

The common personal-social adjustment problems of freshmen in their first few weeks in the university include: not getting involved in social activities, not fitting well in the university environment and not really enjoying life. It can therefore be concluded that freshmen in the University of Cape Coast have issues with social activities and their overall interaction enjoyment within their first few weeks in the university.

\section{Recommendations}

Based on the findings of the study, the researchers recommend that university management make the time table for freshmen more flexible thereby reducing the burden of the academic pressure they experience during their first year. University authorities should ensure that orientation programmes organized for freshmen should be 
continued and tailored more to suit the challenges of freshmen. Intermittent workshops should also be organized by university counselling centre to equip freshmen with the necessary skills to be able to handle the challenges they are likely to encounter.

\section{References}

Ackah, J. Y., \& Kuranchie, A. (2015). Foreign students' adjustment in early days of their university education: The stress and strains. Academic Journal of Interdisciplinary Studies, 4(2), 399-405.

Ahmad, K., Fauziah, N., Azemi, Y., Shaari, M., \& Zailani, M. Y. (2002). Adjustment to college life and academic performance among Universiti Utara Malaysia Students. Unpublished Manuscript. Universiti Utara Malaysia, Kedah, Malaysia.

Akwensivie M, D., Ntiamoah, A. J., \& Obro-Adibo, G. (2013). Foreign students' experience in Ghana. Journal of Education and Practice, 4(28), 99-106.

Al-Dubai, S. A. R., Al-Naggar, R. A., Alshagga, M. A., \& Rampal, K. G. (2011). $\quad$ Stress and coping strategies of students in a medical faculty in Malaysia. Malaysian Journal of Medical Science, 18(3), 57-64.

Al-Qaisy, L. M. (2010). Adjustment of college freshmen: The importance of gender and the place of residence. International Journal of Psychological Studies, 2(1), 142-150.

Baker, R. W., \& Siryk B. (1999). SACQ: Student adaptation to college questionnaire manual (2 ${ }^{\text {nd }}$ ed.). Los Angeles, CA: Western Psychological Services.

Brissette, I., Scheier, M. F., \& Carver, C. S. (2002). The role of optimism in social network development, coping, and psychological adjustment during a life transition. Journal of Personality and Social Psychology, 82(1), $102-111$

Burgess, T., Crocombe, L., Kelly, J., \& Seet, P. S. (2009). The effect of cultural background on the academic adjustment of first year dental students. Ergo, 1(2), 5-24.

Cooke, R., Beewick, B. M., Barkham, M., Bradley, M., \& Audin, K. (2006). Measuring, monitoring and managing the psychological wellbeing of first year university students. British Journal of Guidance \& Counselling, 34(4), 505-517.

Dyson, R., \& Renk, K. (2006). Freshmen adaptation to university life: Depressive symptoms, stress, and coping. Journal of Clinical Psychology, 62(10), 1231-1244.

Folkman, S., \& Lazarus, R. S. (1988). Manual for the ways of coping questionnaire. Palo Alto, CA: Consulting Psychologists Press.

Forde, L. D., \& Brenya, E. E. (2012). Adjustment needs and coping patterns of international students in the University of Cape Coast. International Council on Education for Teaching, 56, 214-231.

Habibah, E., Noordin, N., \& Mahyuddin, R. H. (2010). Achievement motivation and self-efficacy in relation to adjustment among university students. Journal of Social Sciences, 6(3), 333-339.

Madilo, W. (2009). The state of Ghana's university student: Where did we go wrong..? Retrieved from https://www.ghanaweb.com/GhanaHomePage/NewsArchive/The-State-of-Ghana-s-University-Student160479

Mudhovozi, P. (2012). Social and academic adjustment of first-year university students. Journal of Social Science, 33(2), 251-259.

Mutambara, J., \& Bhebe, V. (2012). An analysis of the factors affecting students' adjustment at a university in Zimbabwe. International Education Studies, 5(6), 244-250.

Ngwenya, M. D. (2004). The imaging technique as learning support for educationally disadvantaged learners in the secondary school to improve reading comprehension. Pretoria, South Africa: University of Pretoria.

Park, C. L., \& Adler, N. E. (2003).Coping style as a predictor of health and well-being across the first year of medical school. Health Psychology, 22(6), 627-631.

Parker, J. D. A., Summerfeldt, L. J., Hogan, M. J., \& Hogan, S. A. (2004). Emotional intelligence and academic success: Examining the transition from high school to university. Personality and Individual Differences, $36(1), 163-173$

Rausch, J. L., \& Hamilton, M. W. (2006). Goals and distractions: Explanations of early attrition from traditional university freshmen. The Qualitative Report, 11, 317-334.

Sennett, J., Finchilescu, G., Gibson, K. \& Strauss, R. (2003). Adjustment of black students at a historically white South African university. Educational Psychology, 23(1), 107-116.

Seyedfatemi, N., Tafreshi, M., \& Hagani, H. (2007). Experienced stressors and coping strategies among Iranian nursing students. BMC Nursing, 6(11), DOI: 10.1186/1472-6955-6-11.

Smith, T., \& Renk, K. (2007). Predictors of academic-related stress in college students: An examination of coping, social support, parenting, and anxiety. NASPA Journal, 44(3), 405-431.

Sreeramareddy, C. T., Shankar, P. R., Binu, V. S., Mukhopadhyay, C., Ray, B., \& Menezes, R. G. (2007). Psychological morbidity, sources of stress and coping strategies among undergraduate medical students of Nepal. BMC Med Education, 7(26), 15-21. 
Tao, S., Dong, Q., Pratt, M., Hunsberger, W., \& Pancer, S. (2000). Social support: Relations to coping and adjustment during the transition to university in the People's Republic of China. Journal of Adolescent Research, 15, 123-144.

Thawabieh, A. M., \& Qaisy, L. M. (2012). Assessing stress among university students. American International Journal of Contemporary Research. 2(2), 110-115.

Tinto, V. (1996). Reconstructing the first year of college. Higher Education, 25, 1-6.

Wong, J. G., Cheung, E. P., Chan, K. K., Ma, K. M., \& Tang, S. W. (2006). Web based survey of depression, anxiety and stress in first year tertiary education students in Hong Kong. Australian \& New Zealand Journal of Psychiatry, 40, 777-782. 